\title{
A CLASS OF NEW TRIGONOMETRIC INEQUALITIES AND THEIR SHARPENINGS
}

\author{
Kun ZHU, Hong ZHANG AND KaIQING Weng
}

Abstract. Some sufficient or necessary conditions for Schur-convexity of a function of two variables $F(x, y)=(f(y)-f(x)) /(g(y)-g(x))$ were considered. These results are applied to establish a class new inequalities in a triangle. In the fourth section we prove two theorems for a kind of symmetric function. These theorems are used to sharpen some of the inequalities and yield two inequalities in the last section.

Mathematics subject classification (2000): 26D05; 52A40.

Key words and phrases: Schur-Convexity, Majorization, Trigonometric Inequality.

\section{REFERENCES}

[1] O. BotTema, R. Z. Djordjević, R. R. Janić, D. S. Mitrinović, P. M. Vasić, Geometric Inequalities, Wolters-Noordhoff Groningen, translated into Chinese by Zun San, 16 (1969).

[2] B. C. CARLSON, The Logarithmic Mean., Amer. Math. Monthly, 79 (1972), 615-618.

[3] J. M. CHILD, Unknown Title., Math. Gazette, 23 (1939), 138-143.

[4] A. W. Marshall, I. Olkin, Inequalities: Theory of Majorization and Its Applications., Academic Press, New York, 7 (1979), 64.

[5] Milan Merkle, Conditions for Convexity of A Derivative and Applications to The Gamma and Digamma Function, AFacta Universitatis, Ser. Math. Inform., 16 (2001), 13-20. 